\title{
CHARACTERISATION OF AGRICULTURAL RESIDUES USED AS A SOURCE OF FIBRES FOR FIBRE-CEMENT PRODUCTION
}

\author{
Rocío Jarabo, Ma Concepción Monte*, Angeles Blanco, Carlos Negro and Julio Tijero \\ Chemical Engineering Department. Faculty of Chemistry, University Complutense of Madrid. \\ 28040 - Madrid, Spain, Phone: +34 913944 245, Fax: +34 913944243 \\ e-mail: $\underline{\text { cmonte @quim.ucm.es }}$
}

\section{$\underline{\text { ABSTRACT }}$}

Nowadays, certain components of non-wood annual plants such as corn stalk and industrial hemp core are considered waste materials or used in low value applications; both by-products have a very low cost. On the other hand, given the large quantities of these materials generated worldwide and their renewable character, it is reasonable to explore new routes for their exploitation. The aim of this paper is to study the potential of both corn stalk (Zea Mays L.) and industrial hemp core (Cannabis Sativa L.) fibres as a renewable source of cellulose fibres in the production of fibre-cement. For each source of fibres, a number of chemical cooking treatments were studied. The morphological properties of the fibres were determined using a scanning electron microscope and a fibre and pulp morphological analyser. Pulp refining was carried out in a PFI mill to improve the characteristics of the fibres. In the case of corn fibres, different degrees of refining were applied. The fibre flocculation process was investigated using several polyacrylamides. The process was studied by monitoring the chord size distribution in real time by means of a focused beam reflectance measurement probe. 
25 The results indicated both pulps can be used for the production of fibre-cement,

26 having the two types of pulp morphological similarities with the pine fibres

27 currently used.

28 Through the flocculation process it was concluded the floc size depends on the

29 length of the fibres.

30

31 Keywords: Cannabis Sativa L.; Zea Mays L; natural fibres; fibre-cement;

32 morphological characterisation

33

34

35

36

37

38

39

40

41

42

43

44

45

47

46

48

* Corresponding author: Mํㅡㄹ Concepción Monte. Chemical Engineering Department, U.C.M.

49

Chemistry Faculty. Avda. Complutense s/n, Madrid 28040. Spain. Phone:+34 913944245

cmonte@quim.ucm.es

50 


\section{INTRODUCTION}

52 In recent years, there has been a growing interest in the use of natural fibres in

53 composite materials. This is the case of the fibre-cement industry, especially after

54 the use of asbestos as reinforcing fibres was forbidden due to the health problems.

55 Since then, new technologies for the production of fibre-cement using cellulose and

56 synthetic materials as reinforcement fibres have been developed. Among the

57 potential substitutes for asbestos, four types of fibres are distinguished by their

58 importance, namely steel fibres, glass fibres, synthetic fibres and natural fibres.

59 Fibre-reinforced cement with steel fibres. They are materials characterised for their

60 high resistance, which increases with the fibre length. However, an excessive length

61 may lead to the formation of kinks in the fibres, reducing the mechanical properties

62 of the resulting material. Steel fibres improve significantly the mechanical

63 characteristics of mortars and concrete, in terms of impact strength and toughness.

64 Tensile strength, flexural strength, fatigue strength and ability to resist cracking and

65 spalling are also increased (Qi-sheng et al., 2008; Song and Hwang, 2004; Teng et

66 al., 2008).

67 Fibre-reinforced cement with glass fibres. The main characteristic of glass fibre-

68 reinforced cement composites is the durability of their fibres in the alkaline

69 environment of cement. The long term properties of glass fibre-reinforced cement

70 composites are the reduction in strength and ductility with time. The poor durability

71 of glass fibre-reinforced cement is generally attributed to: (a) degradation of the

72 fibres by hydroxyl ions from the hydrating cement matrix, (b) precipitation of

73 hydration products, especially calcium hydroxide and, (c) densification of the 
74 matrix at the interface (Bentur and Mindess, 1990; Marikunte et al., 1997; Purnell et

75 al., 2000).

76 Fibre-reinforced cement with synthetic fibres. The mechanical properties of

77 materials from synthetic fibre-reinforced cement depend largely on the properties of

78 the individual fibres. Several types of fibres have been tested as reinforcement,

79 among which acrylic, aramid, carbon, nylon, polyester, polyethylene and

80 polypropylene fibres. The improvement in the properties achieved through synthetic

81 fibre-reinforce cements varies, for example, carbon fibres have been used as fillers

82 in cement matrix composites to improve both mechanical and electrical behaviours

83 as well as the electromechanical and electromagnetic behaviours. They can be used

84 in cement together with steel fibres, as the addition of short carbon fibres to steel

85 fibre-reinforced mortar increases the fracture toughness of the interfacial zone

86 between steel fibres and the cement matrix (Guan et al., 2006; Jingyao and Chung,

87 2001; Laukaitis et al., 2009; Song et al., 2005; Wang et al., 2008;).

88 Fibre-reinforced cement with natural fibres. In recent years, considerable efforts

89 have been made to develop natural fibre-reinforced cement composites for

90 affordable infrastructures: from plants, minerals and/or animals. However, the long-

91 term durability of natural fibre-reinforced composites may be limited due to their

92 high permeability and lack of resistance to crack growth, particularly vegetable with

93 fibres obtained from agricultural by-products (Angelini et al., 2000; Savastano et

94 al., 2009). Vegetal fibres as bagasse from sugar cane, bamboo and coconut fibres

95 may be used as an alternative material due to their biodegradability, low specific

96 mass, low cost and availability (Guimarãesa et al., 2009). 
97 Detailed knowledge of the fibre morphology is necessary to evaluate its potential

98 application and the product quality (Bartl et al., 2004; Oksanen et al., 2000).

99 On the other hand, flocculation processes are of great importance in the actual

100 manufacture of fibre-cement, because they affect the formation of plaque, the

101 retention of solids and the drainage of the suspension (Fuente et al., 2010). The

102 flocculants used are generally anionic polyacrylamides with high molecular weight

103 and low-medium electrical charge that induce flocculation by bridges (Jarabo et al.,

104 2010a; Negro et al., 2005; Negro et al., 2006a).

105 In this paper, fibres from agricultural residues, specifically Zea Mays L. and

106 Cannabis Sativa L., have been characterised morphologically to evaluate their

107 potential application as alternative sources of cellulose as reinforcement fibre in

108 fibre-cement manufacturing. For this application the most important properties are

109 morphological characteristics (length, width and presence of microfibrils) and the

110 content of fine particles. These properties have been compared with those of pine

111 fibres commonly used in fibre-cement manufacture (Silva et al., 2008).

112 Moreover, the refining of these fibres has been also studied due to its effects on

113 internal and external fibrillation, fines formation, fibre shortening and fibre curling

114 or straightening, which favours the bonding with the cement particles (Gil et al.,

115 2009; Sain and Fortier, 2002; Vidal et al., 1999).

116 The select the most efficient pulp suspension, the flocculation and floc properties of

117 the different pulp suspensions with anionic and cationic polyacrylamides were

118 studied by a focused beam reflectance measurement technique (FBRM), whose

119 evolution enables to monitor flocculation.

120 2. MATERIALS AND METHODS 


\subsection{Materials}

122 The raw materials used in this study were corn stems (Zea Mays L.) and industrial

123 hemp straws (Cannabis Sativa L.). As reference, unbleached pine kraft pulp refined

124 at $35^{\circ} \mathrm{SR}$ was used. Tables 1 and 2 show the cooking conditions applied to obtain

125 both the hemp and corn pulps by an Organosolv process using ethanolamine and

126 ethanol as solvents, respectively (Akgul and Tozluoglu, 2010; Anatoly and Pereira,

127 2005; Pan et al., 2006).

128 An anionic polyacrylamide (APAM) with a high molecular weight of $7.4 \cdot 10^{6} \mathrm{~g} / \mathrm{mol}$

129 and a cationic polyacrylamide (CPAM) with a medium molecular weight of $5 \cdot 10^{6}$

$130 \mathrm{~g} / \mathrm{mol}$ commonly used in the industrial Hatcheck process were used. They were

131 dissolved in distilled water to prepare solutions with a concentration of $1.5 \mathrm{~g} / \mathrm{L}$.

132 2.2. Methods

$133 \quad$ 2.2.1. Characterisation by a Scanning Electron Microscopy

134 The morphological characterisation of the fibres was carried out by a scanning

135 electron microscope (SEM), JEOL, mod. JM-6400. Each sample was placed on a

136 cylindrical slide and placed in a vacuum oven for 24 hours to be dried. After drying

137 the sample was coated with gold. Then, it was introduced in the SEM and was

138 visualised with a magnification of 100, 500 and 1500 (Li et al., 2009).

139 2.2.2. Characterisation by a Morphological Analyser

140 The morphological characterisation of fibres was performed using a fibre and pulp

141 morphological analyser, Morfi, V7.9.13.E (Techpap, France). The parameter limits

142 to measure these fibres were set as follows: length between 100 and $6000 \mu \mathrm{m}$ and

143 for the width, between 5 and $75 \mu \mathrm{m}$. The morphological performed through the

144 equipment is based on characterisation an image analysis system, consisting of a 
145 diode that emits unpolarised light. Imaging is performed until the equipment counts 1465000 fibres, which is the optimum value for subsequent statistical analysis using a

147 computer software. The final results are obtained both numerically and graphically.

148 The samples were analysed using a specific program to determine different

149 parameters of the fibres and pulps (Jarabo et al., 2010b; Moral et al., 2010).

150 The samples for morphological characterisation were prepared by adding $1 \mathrm{~g}$ of dry

151 corn or hemp to $600 \mathrm{~mL}$ of water and homogenising in an ENJO-model 692 lab

152 disintegrator.

153 The characterisation was done in duplicate. The average values of the two

154 measurements are shown. Although a large number of parameters are measured by

155 this equipment, the parameters selected for the comparison of the different raw

156 materials were the length and the width of fibres, percentage of microfibrils and

157 fines number.

158 2.2.3. Characterisation by Focused Beam Reflectance Measurement

159 The flocculation of the different pulps prepared was studied using a commercial

160 FBRM-M500L, S400 IP 14/206 manufactured by Mettler Toledo, Seattle, USA.

161 The FBRM device measures the chord length distribution in real time over a wide

162 range of solid concentrations in the suspension. A laser beam is projected through

163 the probe and focused on the focal point by means of a rotating lens. The focal point

164 describes a circular path on a $20 \mu \mathrm{m}$ plain outside the surface of the probe,

165 immersed into the suspension, at high rotation speed (2000 rpm). Every time a

166 particle in suspension crosses the circular line circumscribed by the focal point,

167 light is reflected from the surface of the particle and it reaches the detector. A

168 computer calculates the chord length of the particle on the basis of the reflectance 
169 time and focal point speed. Each measurement provides a particle chord length

170 distribution representative of the size and shape of the population of particles in the

171 suspension. The flocculation process of the fibres and fillers in the manufacture of

172 cement, allows the real-time monitoring of all processes involving a change in

173 particle size. The addition of flocculant allows observing the changes that occur in

174 the solution during the flocculation process (Blanco et al., 2002; Negro et al., $1752006 b)$.

176 In a typical trial, the probe was immersed in $400 \mathrm{~mL}$ of fibre suspension, prepared

177 with $\mathrm{Ca}(\mathrm{OH})_{2}$ saturated water and stirred at $800 \mathrm{rpm}$. After $6 \mathrm{~min}$., the stirring

178 intensity was reduced to $400 \mathrm{rpm}$ and maintained for 2 minutes, after which 100

179 ppm of PAM were added to induce the floc. The evolution of the flocs was

$180 \quad$ subsequently studied at $400 \mathrm{rpm}$ for $4 \mathrm{~min}$.

$181 \quad$ 2.2.4. Refining process

182 The refining process of corn stalks fibres was carried out under controlled

183 conditions, using the PFI mill (ISO 5264/2-2003). The industrial hemp core was not 184 refined due to its high hardness. The refining of corn residue pulp was performed in 185 three stages:

186 Disintegration of the pulp by means of a lab disintegrator ENJO model 692

187 according to ISO 5263 and ISO/DP 625: $30 \mathrm{~g}$ of dried pulp were disintegrated in 2

188 L of water to obtain a final pulp consistency of $1.5 \%$. It was programmed to

189 disintegrate at 9000 revolutions per minute.

190 Pulp refining was performed by a PFI mill at $10 \%$ consistency according to ISO

$1915264 / 2$. The revolutions number applied in each corn pulp is summarised in Table 1923. 
193 The degree of pulps refining was measured using a Canadian Standard Freeness

194 (CSF), according to ISO 5267/2.

195 3. RESULTS AND DISCUSSION

196 3.1. Morphological characterisation

197 Each fibre sample was characterized by duplicate. The variability of the

198 morphological parameters (RSD) was determined by Equation [1] (Spiegel, 1993).

$199 R S D(\%)=\left[\left(X_{\mathrm{i}}-X_{\text {average }}\right) / X_{\text {average }}\right] \cdot 100$

200 Where, $R S D$ is the variability of the parameter $(\%) ; X_{\mathrm{i}}$ represents the measured

201 value; and $X_{\text {average }}$ represents the mean value of the two measurements. Length and

202 width measurements showed less than $0.5 \%$ of variability and microfibrils and fines

203 number measurements around $2 \%$.

$204 \quad$ 3.1.1. Hemp core

205 The morphological characterisation results of hemp core and pine pulps, obtained

206 by Morfi are shown in Table 4.

207 The length and the width of hemp fibres are very similar to each other, but a slight

208 decrease in the value of these parameters was observed when cooking conditions

209 were harsher. The most important factors affecting these parameters are temperature

210 and time since the ethanolamine concentration is constant (Pulp A and B) and the

211 morphological parameters will change (Table 1 and 4). Hemp fibres were shorter

212 than pine fibres in all cases. However, the value of hemp fibres width was similar to

213 pine fibres when cooking conditions were milder.

214 The quantity of microfibrils in the processed hemp samples increased when cooking

215 conditions were harsher. This increase in the percentage of microfibrils improves

216 the cross linking with other fibres, and consequently, the mechanical properties of 
217 the final material. The microfibrils percentage of the fibres of pulp D (harsher

218 cooking conditions) became similar to that in pine fibres.

219 In the case of fines number, the most influencing factor is the concentration used in 220 the cooking process. Pulps A and B were obtained using the same ethanolamine 221 concentration. It was observed that the number of fines was practically the same in 222 both cases. An increase in the concentration of ethanolamine implied a reduction in 223 the fines number. The number of fines in pine pulp was very high compared to 224 hemp pulps. A higher number of fines improves retention in the formation of fibre225 cement but reduces the resistance (Fuente et al., 2010).

226 Fig. 1 shows photographs of hemp fibres, obtained by SEM at different cooking 227 conditions shown in Table 1. It was observed that the degree of deterioration in the 228 fibres structure was greater at more aggressive cooking conditions. The 229 deterioration of the fibres can be observed in the breaking of the structure due to the 230 holes produced in the fibre and they are visible only in pulps C and D, pulps 231 obtained by more aggressive cooking conditions.

\section{$232 \quad$ 3.1.2. Corn stalk}

233 The morphological characterisation results from corn pulps are shown in Table 5.

234 In this case, when cooking conditions were harsher, the length of corn fibres was

235 larger but the percentage of microfibrils decreased. These results are contrary to

236 those expected and may be due to the union of microfibrils, which produces

237 agglomerated fibres which are consequently longer.

238 The width of corn fibres, as in the case of hemp fibres, was narrower when cooking 239 conditions were harsher. The width of corn fibres for pulp 4 was similar to pine 240 fibres when cooking conditions were harsher. 
241 In the case of fines number, the main factor affecting was observed to be the

242 temperature. When cooking temperature was lower, the fines number of corn pulps

2431 and 2 was lower. When cooking temperature was increased in corn pulps 3 and 4,

244 the fines number increased. Comparing pulps cooked at the same temperature, pulps

$245 \quad 1$ and $2\left(165^{\circ} \mathrm{C}\right)$, and pulps 3 and $4\left(185^{\circ} \mathrm{C}\right)$ the fines number decreased when the

246 concentration of ethanolamine and cooking time were increased. Fines number in

247 corn pulps was much higher than in hemp pulps. The value of fines number of corn

248 pulp 1 was similar in value to that in pine pulp.

249 Fig. 2 shows photographs of corn fibres obtained by image SEM. Visually the

250 degree of deterioration of corn fibres was more difficult to identify in the case of

251 corn pulps than in the case of hemp pulps due to the cooking conditions.

$252 \quad 3.1 .3$. Effect of refining on the morphological properties of corn pulp

253 As mentioned above, hemp pulps could not be mechanically refined due to their

254 hardness. Then, only the effect of refining could be studied in the case of corn

255 pulps. The effect of refining measured in the Canadian standard freeness (CSF),

256 expressed as volume in $\mathrm{mL}$, and the morphological characteristics of corn fibres are

257 shown in Fig. 3. A high CSF value (volume in $\mathrm{mL}$ ) indicates a low degree of

258 refining.

259 As expected, the length and width of the fibres decreased when the degree of

260 refining was increased. This may be due to the wear experienced by fibres in the

261 refining process, leading to an increase in the fines number and percentage of

262 microfibrils. This increase in percentage of microfibrils enhances the cross linking

263 of fibres, forming a more stable network for the formation of fibre-cement. 
264 Fig. 4 shows SEM images of corn fibres, obtained before and after refining the 265 pulp. It can be observed that the fibres are broken when they are refined (low

266 quantity of volume $\mathrm{mL}$ ). This confirms that the length and width of the fibres are 267 decreasing, thereby the number of fines increased.

268 When the concentration of ethanol was increased, the degree of refining achieved in

269 the pulps was higher (using less revolutions, see Table 3), and therefore they had a $270 \quad$ lower CSF (volume in $\mathrm{mL}$ ).

271 For the pulps obtained at high concentrations of ethanol and high cooking

272 temperature (pulps 3 and 4), the refining of fibres with the PFI required less energy

273 to achieve the same refining achieved in pulp 1 and 2.

274 Thus, it is better to use pulps obtained at aggressive cooking conditions to obtain a

275 more refined pulp (less volume in $\mathrm{mL}$ ) using a lower amount of energy in the 276 refining process.

277 As shown in Fig. 3.c, pulp refining produces an external fibrillation of the cells, 278 what allows flexibility and the formation of bridges with other fibres.

$279 \quad$ 3.2. FBRM characterisation

$280 \quad 3.2 .1$. Flocculation trials using hemp core

281 Fig. 5 shows the flocculation monitored for each hemp pulp with and without

282 flocculant. Mean chord size $(\mu \mathrm{m})$ is represented versus time. It is observed that the 283 addition of flocculant led to an increase in the mean chord size.

284 In general, fibres are themselves flocculated mechanically, so it was difficult to 285 induced flocculation and increase the mean chord size (Jarabo et al., 2010a). The 286 APAM shows better results than the CPAM in all the pulps. 
287 In Fig. 6, the comparison between the different hemp pulps and the pine pulp using

288 APAM is shown. It can be observed that there may be two factors that influencing 289 the fibres mean chord size:

290 Fibres length. When the lengths of the fibres are longer the mean chord size is 291 higher and more flocculation is produced, as it was the case of pulp A, (which has 292 the low cooking conditions). The mean chord size decreased each time the fibre 293 length decreased as well.

294 Microfibrils. When the quantity of microfibrils increases the mean chord of the 295 floc decreases and the flocculation is lower.

296 Then, it can be concluded that the decrease of fibre length and the increase in the 297 percentage of microfibrils lead to a decrease in floc size, what means that 298 flocculation takes place to a lower extent.

299 Comparing the floc size of hemp fibres with pine fibres it can be observed that the $300 \quad$ latter present larger sizes due to the length of pine fibres, $1130 \mu \mathrm{m}$, compared to 301 that of hemp fibres, the larger of which was found to be pulp A, with a length of $302509 \mu \mathrm{m}$. Despite this difference with pine fibre, there are similarities between the 303 two pulp types. For example, the width of pulp A fibres and the quantity of 304 microfibrils of pulp D are comparable to those of pine fibres. In view of these 305 results, the two above mentioned hemp fibres were selected to study their potential 306 as reinforcement in fibre-cement sheets.

\section{$307 \quad 3.2 .2$. Flocculation trials of corn stalk}

308 Fig. 7 shows the graphs for each corn pulp with and without flocculant.

309 In these pulps, unlike hemp fibres, flocculation was less noticeable when the 310 flocculant was added. The corn fibres are flocculated mechanically too, so it is 
311 difficult to induce flocculation (Jarabo et al., 2010a), but there was a small increase

312 in the floc size when APAM is added instead of CPAM.

313 In this case, the factor influencing the mean chord size was mostly the length and

314 number microfibrils. When the fibres length increased and the microfibrils

315 decreased, the mean chord size increased and, therefore, the size of the floc was

316 greater.

317 With corn fibres, unlike with hemp, the harsher the cooking conditions employed,

318 the greater the length of the fibres and lower the percentage of microfibrils were.

319 Fig. 8 shows that pulps 1 and 3 reach a similar floc size despite starting from

320 different fibre lengths. Pulps 1 and 3 have smaller floc size than pulp 2. It is

321 concluded, in addition to fibre length, another factor that affecting the floc size of

322 the corn pulp is the "cooking time" of the raw material.

323 Comparing the mean chord size of corn fibres with pine fibres, it was found that

324 pine fibre flocs had larger size due to the length of pine fibres, $1130 \mu \mathrm{m}$, compared

325 with corn fibres. Nevertheless, in this case the difference with the corn pulp 4 (734

$326 \mu \mathrm{m})$ is smaller than in the case of hemp fibres $(509 \mu \mathrm{m})$. Pulp 4 also presented fibre

327 widths and number of fines similar to those of pine pulps. Based on those

328 characteristics pulp 4 was selected to be studied as further a reinforcement material

329 in fibre-cement sheets.

$330 \quad$ 3.2.3. Flocculation trials of corn stalk refining

331 Fig. 9 and 10 show the results of the flocculation tests carried out with refined corn 332 pulps 1 and 3 respectively.

333 An important factor regarding the flocculation is the length of the fibres which is 334 directly influenced, as shown in fig. 3, by the process of refining. 
335 As expected, Fig. 9 shows that pulps obtained at less aggressive cooking conditions

336 (pulp 1) need more energy to be refined process, whereas Fig. 10 shows that the

337 pulp obtained at more aggressive cooking conditions (pulp 4) need less energy in

338 the refining. This factor is very important from the environmental point of view.

341 The selection of suitable cooking conditions to obtain hemp and corn pulps is

342 important for the morphological characteristics of the fibres, and, therefore, for their 343 application in the fibre-cement manufacture.

344 In the studied conditions, corn fibres are longer and wider than those of hemp. Both

345 types of fibres have similar microfibrils contents, but corn fibres show higher

346 contents of fine elements.

347 When cooking conditions are aggressive, hemp fibres are shorter, narrower, have

348 more microfibrils percentage and lower number of fines. Hemp fibres and pine

349 fibres have the same width and percentage of microfibrils when cooking conditions

$350 \quad$ are milder.

351 When cooking conditions are more aggressive, corn fibres are longer, narrower and

352 have a lower microfibrils percentage. Corn fibres and pine fibres have the same

353 width and similar length and fines number when cooking conditions are harsher.

354 The number of fines does not follow a clear trend.

355 Refining produces defibrillation of corn fibres. Therefore a homogeneous mixture

356 with the appropriate level of defibrillated fibres can be obtained, in suspensions of

357 fibre-cement without affecting retention. 
358 Natural fibres commonly need to be sized to a specific dimension for a particular 359 application. Floc size depends on the length of fibres and, in the specific case of $360 \quad$ corn fibres, it depends on the cooking conditions.

361 From these results, it may be concluded that the two types of pulps studied can be 362 used as reinforcement fibres for the manufacture of fibre-cement. At certain 363 cooking conditions, the fibres from corn pulps and from hemp pulps can be made so 364 as to have similarities with the pine fibres often used in this industry.

365

$366 \quad$ Acknowledgments

367 The authors wish to acknowledge the financial support of the Ministry of Science 368 and Innovation of Spain to the Project CTM2007-66793-C03-03 and for funding the 369 scholarship of Ms Rocío Jarabo in order to accomplish her PhD Thesis. The authors 370 would also like to acknowledge the contribution of the LEPAMAP group of the $371 \quad$ University of Girona in supplying hemp and corn pulps.

372 373 374 375 REFERENCES

376 Akgul, M., Tozluoglu, A. 2010. Alkaline-ethanol pulping of cotton stalks. Sci. Res. $377 \quad$ Essays. 5, 1068-1074. 378 379 Anatoly, A. S., Pereira, H., 2005. Kinetics of organosolv delignification of fibre 380 crop Arundo donax L. Ind. Crops Prod. 21, 203-210. 
Angelini, L.G., Lazzeri, A., Levita, G., Fontanelli, D., Bozzi, C., 2000. Ramie

383

(Boehmeria nivea (L.) Gaud.) and Spanish Broom (Spartium junceum L.) fibres for

384

composite materials: agronomical aspects, morphology and mechanical properties.

385

Ind. Crops Prod. 11, 145-161.

386

387 Bartl, A., Mihalyi, B., Marini I., 2004. Applications of Renewable Fibrous

388 Materials. Chem. Biochem. Eng. Q. 18(1), 21-28.

389

390 Bentur, A., Mindess, S., 1990. Fibre Reinforced Cementitious Composites, Elsevier

$391 \quad$ London, UK.

392

393 Blanco, A., Fuente, E., Negro, C., Tijero, J., 2002. Flocculation monitoring: focused

394 beam reflectance measurement as a measurement tool. Can. J. Chem. Eng. 80 (4), $395 \quad 734-740$.

396

397 Fuente, E., Jarabo, R., Moral, A., Blanco, A., Izquierdo, L., Negro, C., 2010. Effect

398 of sepiolite on retention and drainage of suspensions of fiber-reinforced cement.

$399 \quad$ Constr. Build. Mater. 24, 2117-2123.

400

401 Gil, N., Gil, C., Amaral, M.E., Costa A.P., Duarte, A.P., 2009. Use of enzymes to

402 improve the refining of a bleached Eucalyptus globules kraft pulp. Biochem. Eng. J.

$403 \quad 46,89-95$.

404 
405 Guan, H., Liu, S., Duan, Y., Cheng J., 2006. Cement based electromagnetic

406 shielding and absorbing building materials. Cem. Concr. Compos. 28, 468-474.

407

408 Guimarãesa, J.L., Frollini, E., da Silva, C.G., Wypychc, F., Satyanarayana, K.G., 409 2009. Characterization of banana, sugarcane bagasse and sponge gourd fibers of $410 \quad$ Brazil. Ind. Crops Prod. 30, 407-415.

411

412 Jarabo, R., Fuente, E., Moral, A., Blanco, A., Izquierdo, L., Negro, C., 2010a.

413 Effect of sepiolite on the flocculation of suspensions of fibre-reinforced cement. 414 Cem. Concr. Res. 40, 1524-1530.

415

416 Jarabo, R., Monte, M.C., Blanco, A., Negro, C., Pelach, M.A., Mutje, P, Tijero, J.,

417 2010b. Morphological and physical characterization of agricultural residues as a 418 source of fibres for papermaking. XXI TECNICELPA Conference and Exhibition / 419 VI CIADICYP 2010. 12-15 October 2010, Lisbon, Portugal.

421 Jingyao, C., Chung, D.D.L., 2001. Carbon fiber reinforced cement mortar improved 422 by using acrylic dispersion as an admixture. Cem. Concr. Res. 31, 1633-1637.

423

424 Laukaitis, A., Keriene, J., Mikulskis, D., Sinica, M., Sezemanas, G., 2009.

425 Influence of fibrous additives on properties of aerated autoclaved concrete forming 426 mixtures and strength characteristics of products. Constr. Build. Mater. 23, 3034$427 \quad 3042$. 
429 Li, Y., Pickering, K.L., Farrell, R.L. 2009. Analysis of green hemp fibre reinforced

430 composites using bag retting and white rot fungal treatments. Ind. Crops Prod. 29,

$431 \quad 420-426$.

432

433 Marikunte, S., Aldea, C., Shah, S.P., 1997. Durability of Glass Fiber Reinforced

434 Cement Composites: Effect of silica fume and metakaolin. Adv. Cem. Based.

$435 \quad$ Mater. 5 100-108.

436

437 Moral, A., Monte, M.C., Cabeza, E., Blanco, A., 2010. Morphological

438 characterization of pulps to control paper properties. Cellulose Chem. Technol. 44

$439 \quad(10), 473-480$.

440

441 Sain, M., Fortier, D., 2002. Flax shives refining, chemical modification and

442 hydrophobisation for paper production. Ind. Crops Prod. 15, 1-13.

443

444 Negro, C., Blanco, A., Fuente, E., Sánchez, L.M., Tijero, T., 2005. Influence of

445 flocculant molecular weight and anionic charge on flocculation behaviour and on

446 the manufacture of fiber cement composites by the Hatschek process. Cem. Concr.

$447 \quad$ Res. 35, 2095-2103.

448

449 Negro, C., Sánchez, L.M., Fuente, E., Blanco, A., Tijero, J., 2006a. Polyacrylamide

450 induced flocculation of a cement suspension. Chem. Eng. Sci. 61, $2522-2532$.

451 
452 Negro, C., Blanco, A., San Pío, I., Tijero, J., 2006b. Methodology for flocculant 453 selection in fiber cement manufacture. Cem. Concr. Res. 28, 90-96.

455 Oksanen, T., Pere, J., Paavilainen, L., Buchert, J., Viikari, L., 2000. Treatment of 456 recycled kraft pulps with Trichoderma reesei hemicellulases and cellulases. J.

$457 \quad$ Biotechnol. 78, 39-48.

458

459 Pan, X., Kadla, J.F., Ehara, K., Gilkes, N., Saddler, J.N., 2006. Organosolv Ethanol

460 Lignin from Hybrid Poplar as a Radical Scavenger: Relationship between Lignin

461 Structure, Extraction Conditions, and Antioxidant Activity. J. Agric. Food Chem.

$462 \quad 54,5806-5813$.

463

464 Purnell, P., Short, N.R., Page, C.L., Majumdar, A.J., 2000. Microstructural

465 observations in new matrix glass fibre reinforced cement. Cem. Concr. Res. 30, $466 \quad 1747-1753$.

467

468 Qi-sheng, W., Xi-bing, L., Guo-yan, Z., Peng, S., Jin-rui, Y., 2008. Experiment on 469 mechanical properties of steel fiber reinforced concrete and application in deep $470 \quad$ underground engineering. J. China Univ. Min. Tech. 18, 0064-0066.

472 Savastano, Jr. H., Santos, S.F., Radonjic M., Soboyejo, W.O., 2009. Fracture and 473 fatigue of natural fiber-reinforced cementitious composites, Cem. Concr. Compos. $474 \quad 31,232-243$.

475 
476 Silva, M.C., Lopes, O.R., Colodette, J.L., Porto, A.O., Rieumont, J., Chaussyd, D.,

477 Belgacem, M.N., Silva, G.G., 2008. Characterization of three non-product materials

478 from a bleached eucalyptus kraft pulp mill, in view of valorising them as a source

479 of cellulose fibres. Ind. Crops Prod. 27, 288-295.

480

481 Song, P.S., Hwang, S., 2004. Mechanical properties of high-strength steel fiber-

482 reinforced concrete Constr. Build. Mater. 18, 669-673.

483

484 Song, P.S., Hwang, S., Sheu, B.C., 2005. Strength properties of nylon- and

485 polypropylene-fiber-reinforced concretes. Cem. Concr. Res. 35, 1546- 1550.

486

487 Spiegel, M.R.,(1993) - Estadística. Ed. Mc Graw Hill. ISBN 84-7615-562X.

488

489 Teng, T.L., Chu, Y.A., Chang, F.A., Shen, B.C., Cheng, D.S., 2008. Development

490 and validation of numerical model of steel fiber reinforced concrete for high-

491 velocity impact, Comput. Mater. Sci. 42, 90-99.

492

493 Vidal, T., Colom, J.F., Gutiérrez, J., López, D., Torres, A.L., 1999. Modifications

494 of fibre and paper properties in secondary fibres by cellulases and hemicellulases.

495 In: 27th EUCEPA Conference. Crossing the Millennium Frontier Emerging

496 Technical and Scientific Challenges. Grenoble, October 11-14. pp. 195-198.

497 
498 Wang, C., Li, K.Z., Li, H.J., Jiao, G.S., Lu, J., Hou, D.S, 2008. Effect of carbon

499 fiber dispersion on the mechanical properties of carbon fiber-reinforced cement-

500 based composites Mater. Sci. Eng., A. 487, 52-57.

501

502 
Fig. 1. Hemp images obtained by SEM with an increase of 1500. Fibres from: a) pulp A, b) pulp B; c) pulp C and d) fibre from pulp D.

Fig. 2. Corn image by SEM with magnification 1500. Fibres from: a) Pulp 1; b) pulp 2; c) pulp 3 and d) pulp 4 .

Fig. 3. Effect of refining on morphological characteristics of corn fibres. a) length, b) width, c) microfibrils and d) fines number.

Fig. 4. Corn image by SEM with magnification 1500. Pulp 1: 40\% ethanol-60 min$165^{\circ} \mathrm{C}$. a) Before refining, b) increased 800 and c) increase 1500 after refining.

Fig. 5. Mean chord size with and without flocculant in fibres of hemp. a) Pulp A, b) Pulp B, c) Pulp C and f) Pulp D.

Fig. 6. Mean chord size with anionic polyacrylamide in fibres of hemp and pine.

Fig. 7. Mean chord size with and without flocculant in fibres of corn. a) Pulp 1, b) Pulp 2, c) Pulp 3 y d) Pulp 4.

Fig. 8. Mean chord size with anionic polyacrylamide in fibres of corn and pine.

Fig. 9. Mean chord size with anionic polyacrylamide in refined corn pulp 1.

Fig. 10. Mean chord size with anionic polyacrylamide in refined corn pulp 3. 


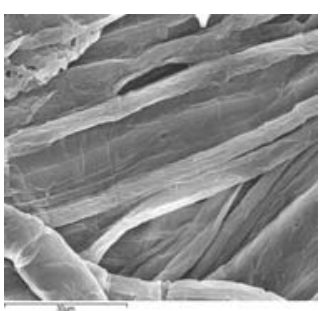

a)

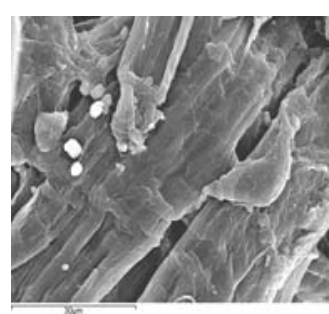

b)

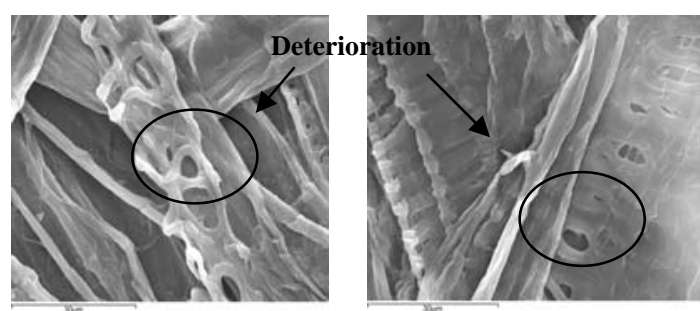

c)

d)

Fig. 1. Hemp images obtained by SEM with an increase of 1500 . Fibres from: a) pulp A, b) pulp B; c) pulp C and d) fibre from pulp D. 


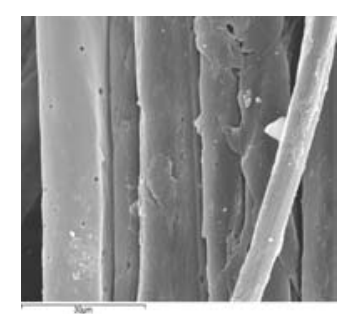

a)

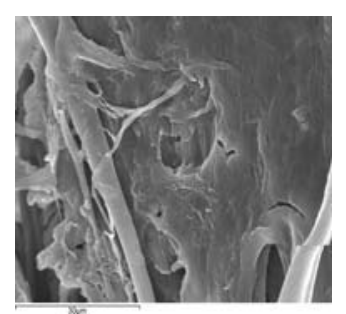

b)

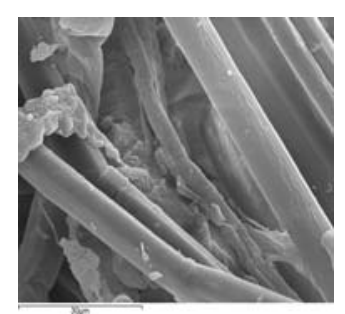

c)

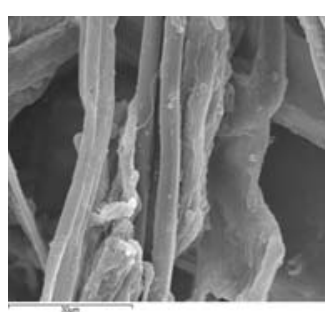

d)

Fig. 2. Corn image by SEM with magnification 1500. Fibres from: a) Pulp 1; b) pulp 2; c) pulp 3 and d) pulp 4. 


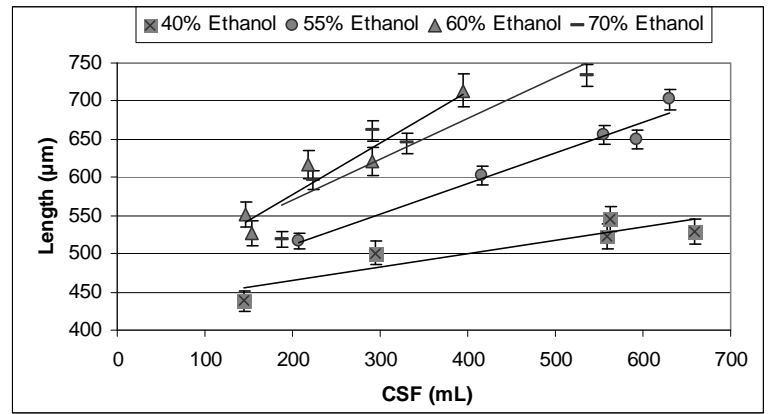

a)

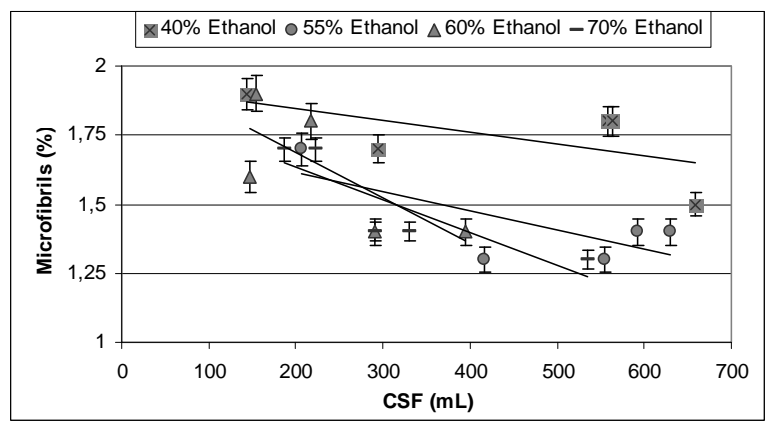

c)

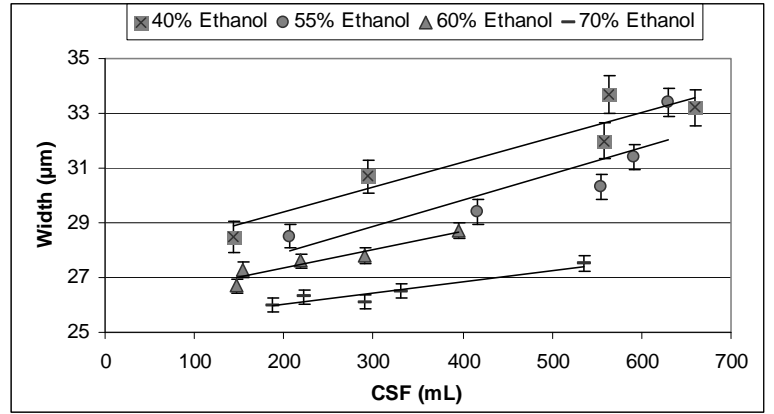

b)

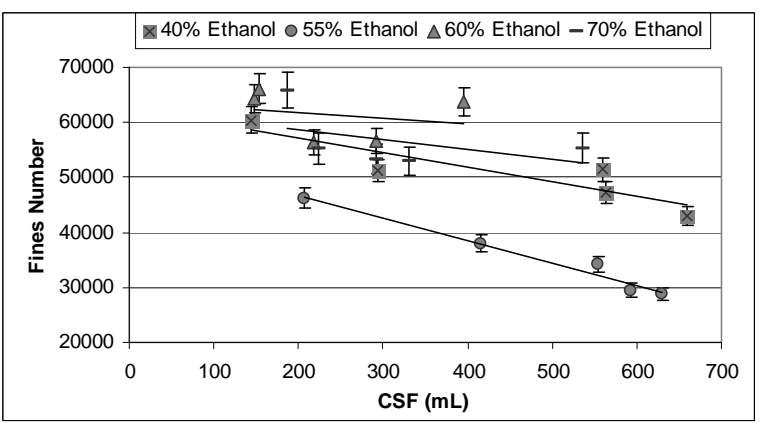

d)

Fig. 3. Effect of refining on morphological characteristics of corn fibres. a) length, b) width, c) microfibrils and d) fines number. 


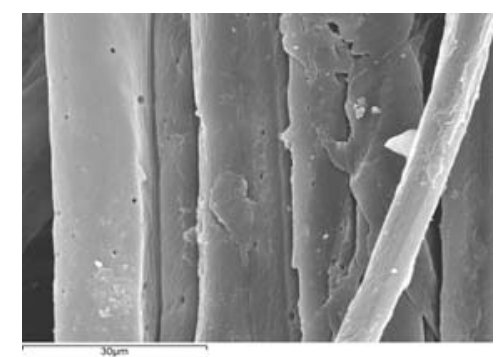

a)

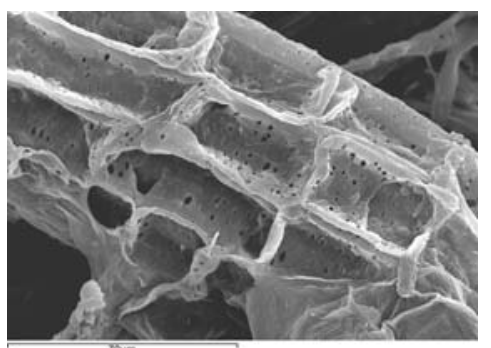

b)

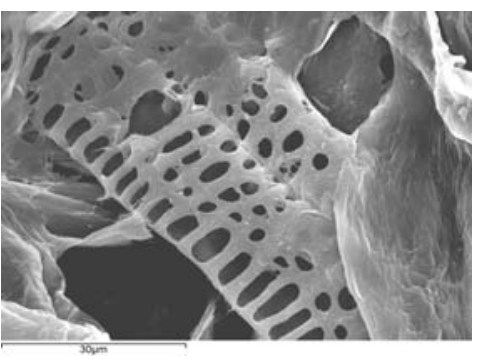

c)

Fig. 4. Corn image by SEM with magnification 1500. Pulp 1: $40 \%$ ethanol-60 min- $165^{\circ} \mathrm{C}$. a) Before refining, b) increased 800 and c) increase 1500 after refining. 


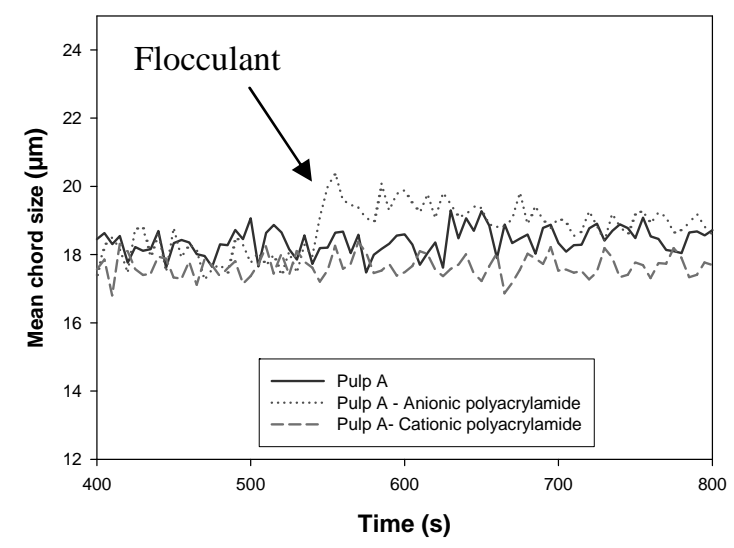

a)

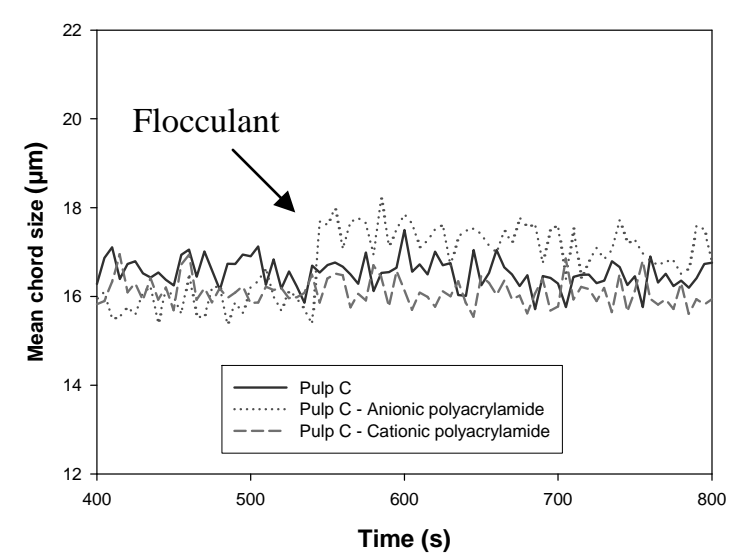

c)

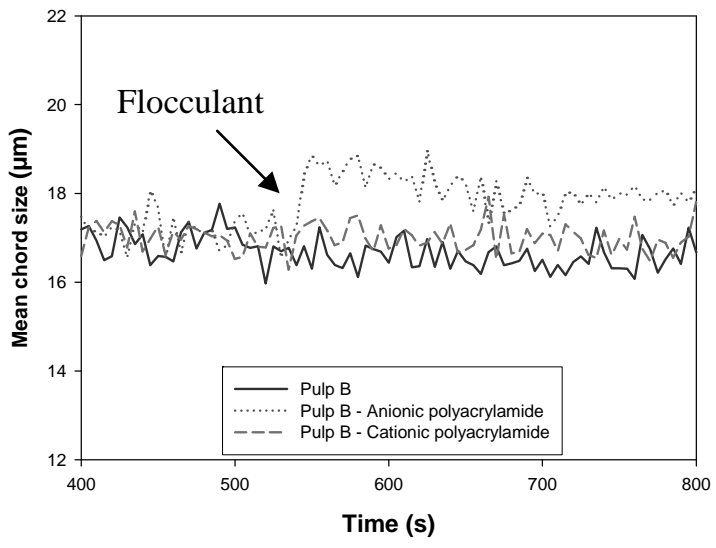

b)

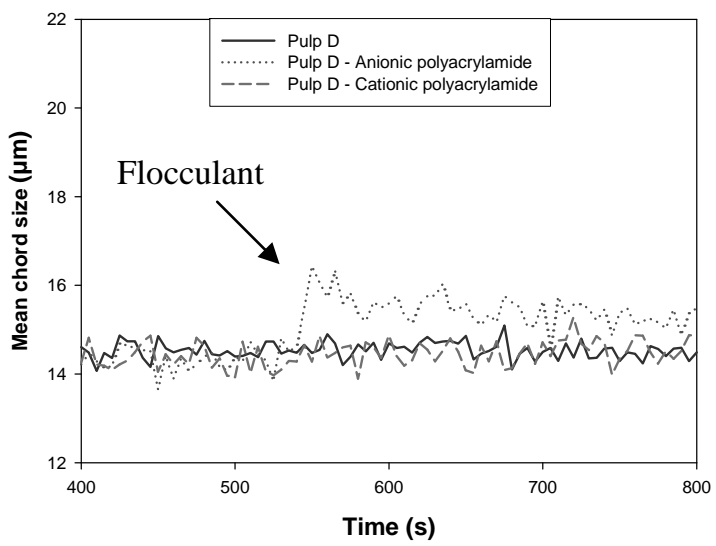

d)

Fig. 5. Mean chord size with and without flocculant in fibres of hemp. a) Pulp A, b) Pulp B, c) Pulp C and f) Pulp D.

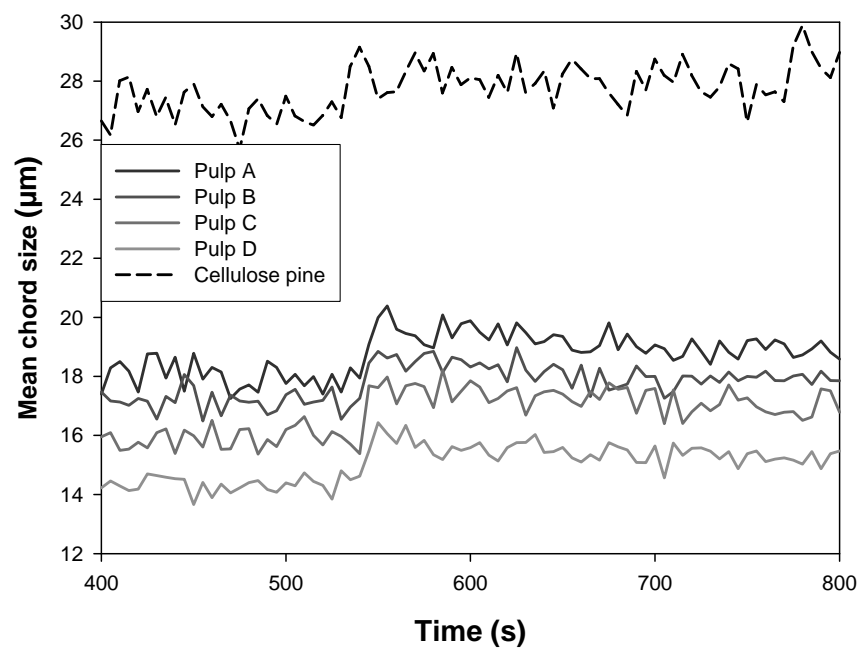


Fig. 6. Mean chord size with anionic polyacrylamide in fibres of hemp and pine. 

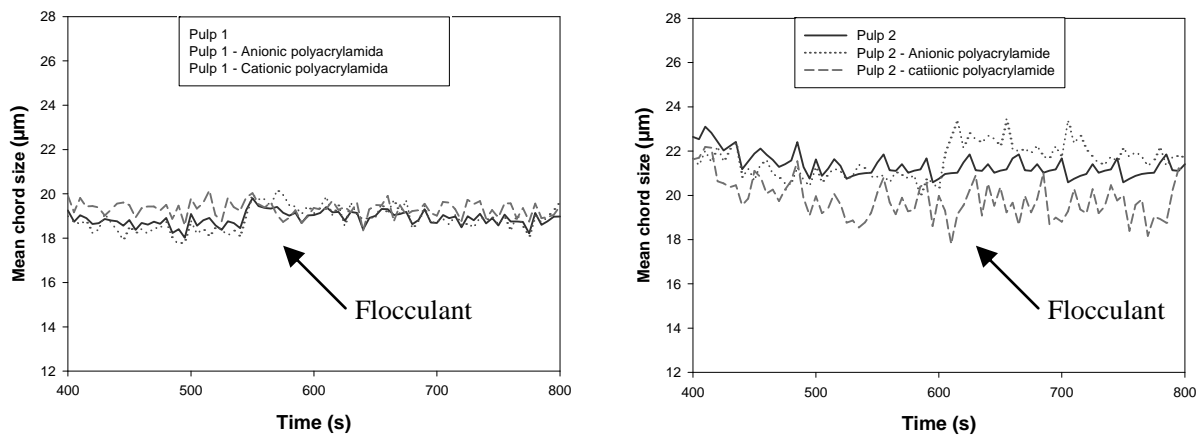

a)
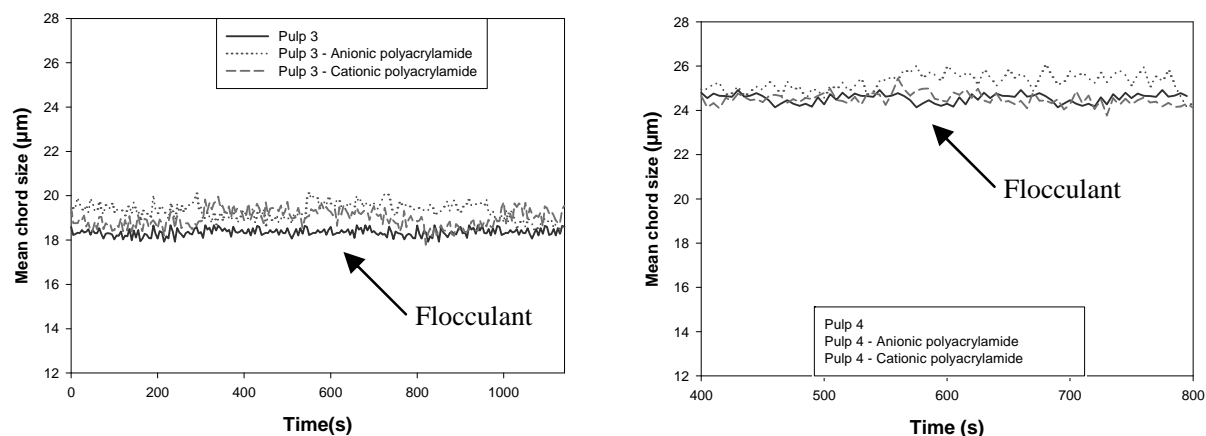

c)

d)

Fig. 7. Mean chord size with and without flocculant in fibres of corn. a) Pulp 1, b) Pulp 2, c) Pulp 3 y d) Pulp 4. 


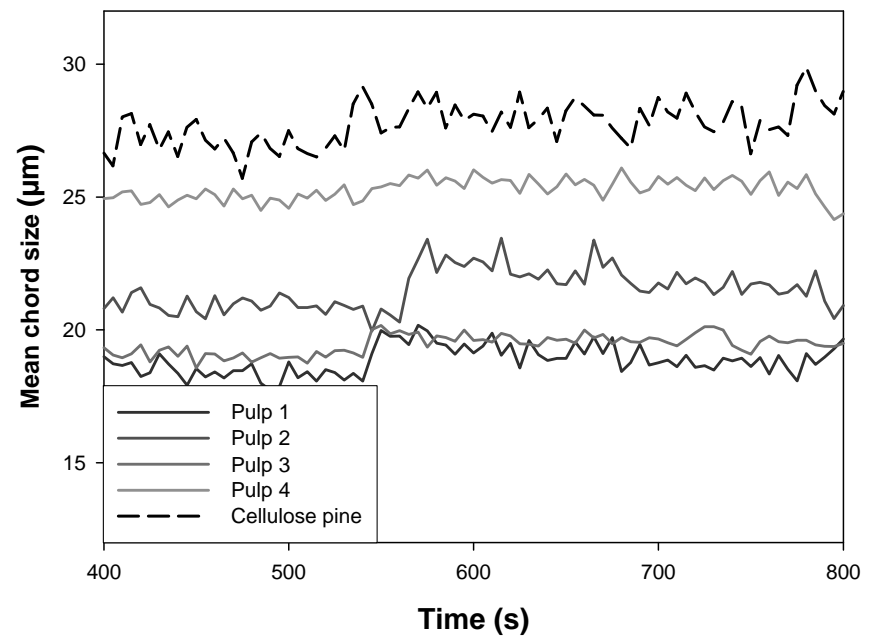

Fig. 8. Mean chord size with anionic polyacrylamide in fibres of corn and pine. 


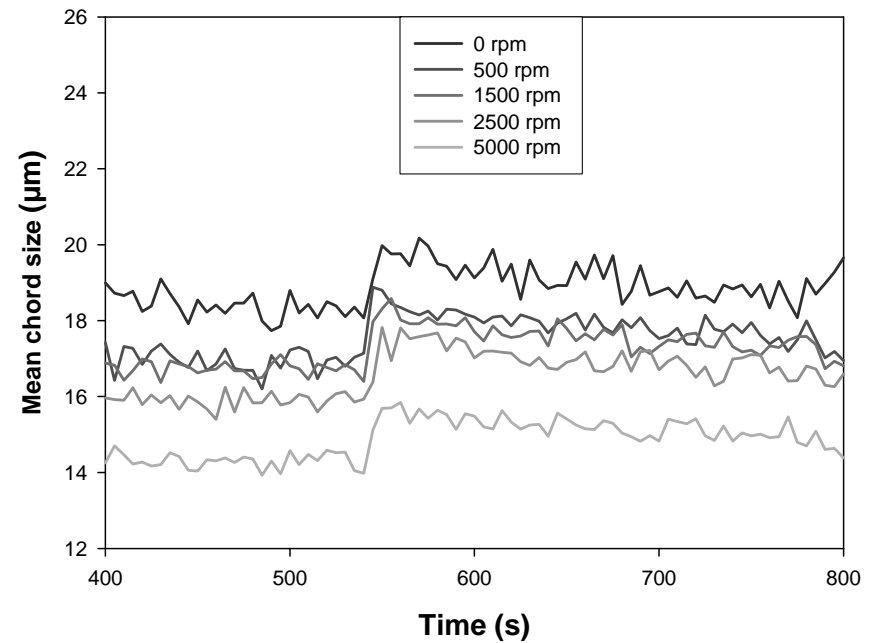

Fig. 9. Mean chord size with anionic polyacrylamide in refined corn pulp 1. 


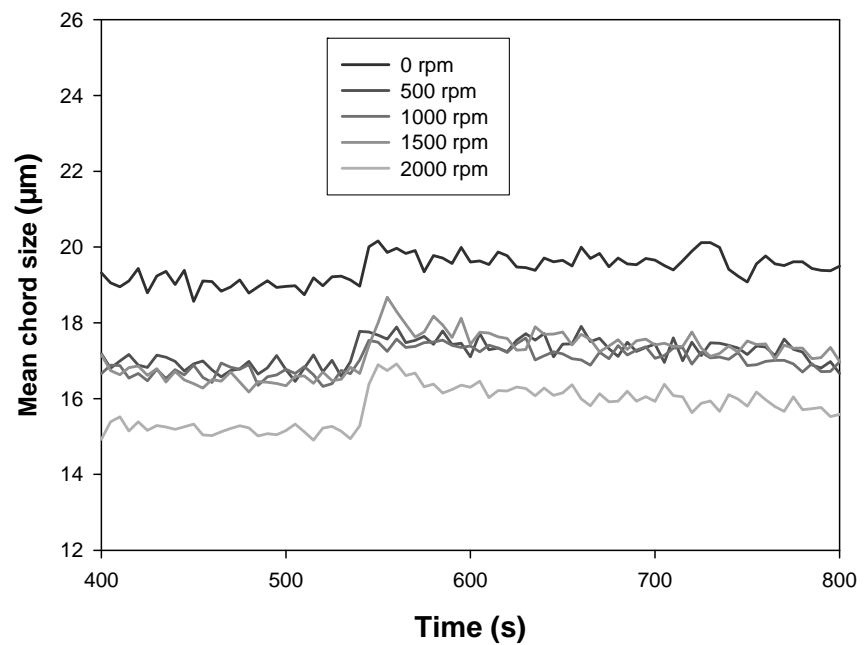

Fig. 10. Mean chord size with anionic polyacrylamide in refined corn pulp 3. 
Table 1. Cooking conditions of hemp using ethanolamine.

\begin{tabular}{|c|c|c|c|}
\hline & Ethanolamine (\%) & Time (min) & Temperature $\left({ }^{\circ} \mathrm{C}\right)$ \\
\hline Pulp A & 40 & 30 & 155 \\
\hline Pulp B & 40 & 60 & 170 \\
\hline Pulp C & 50 & 60 & 170 \\
\hline Pulp D & 60 & 90 & 185 \\
\hline
\end{tabular}


Table 2. Cooking conditions of corn using ethanol.

\begin{tabular}{|c|c|c|c|}
\hline & Ethanol (\%) & Time (min) & Temperature $\left({ }^{\circ} \mathrm{C}\right)$ \\
\hline Pulp 1 & 40 & 60 & 165 \\
\hline Pulp 2 & 55 & 90 & 165 \\
\hline Pulp 3 & 60 & 60 & 185 \\
\hline Pulp 4 & 70 & 120 & 185 \\
\hline
\end{tabular}


Table 3. Revolutions number of each corn pulp.

\begin{tabular}{ll}
\hline Pulp & Revolutions number \\
\hline 40\% Ethanol & $0-500-1500-2000-5000$ \\
$55 \%$ Ethanol & $0-500-1500-2000-5000$ \\
60\% Ethanol & $0-500-1000-1500-2000$ \\
$70 \%$ Ethanol & $0-250-500-1000-1500$ \\
\hline
\end{tabular}


Table 4. Morphological characterization of hemp pulps at different cooking conditions and pine pulp.

\begin{tabular}{lccccc}
\hline Pulp & A & B & C & D & Pine \\
\hline Length weighted in length $(\mu \mathrm{m})$ & 509 & 500 & 497 & 483 & 1130 \\
Average Width $(\mu \mathrm{m})$ & 23,4 & 21,5 & 21,5 & 21,1 & 25,5 \\
Microfibrils $(\%)$ & 1,2 & 1,3 & 1,4 & 1,6 & 1,6 \\
Fines number & 9324 & 9910 & 7973 & 7683 & 49192 \\
\hline
\end{tabular}


Table 5. Morphological characterization of corn pulp at different cooking conditions.

\begin{tabular}{lccccc}
\hline Pulp & $\mathbf{1}$ & $\mathbf{2}$ & $\mathbf{3}$ & $\mathbf{4}$ & Pine \\
\hline Length weighted in length $(\mu \mathrm{m})$ & 529 & 702 & 714 & 734 & 1130 \\
Average Width $(\mu \mathrm{m})$ & 33,2 & 33,4 & 28,7 & 27,5 & 25,5 \\
Microfibrils $(\%)$ & 1,5 & 1,4 & 1,3 & 1,3 & 1,6 \\
Fines number & 42938 & 28766 & 63726 & 55299 & 49192 \\
\hline
\end{tabular}

